Document downloaded from:

http://hdl.handle.net/10251/158495

This paper must be cited as:

Vidal Garcia, R.; Ribal, J. (2019). Terminal Value in SMEs: Testing the Multiple EV/EBITDA Approach. Journal of Business Valuation and Economic Loss Analysis (Online). 14(1):1-11. https://doi.org/10.1515/jbvela-2018-0012

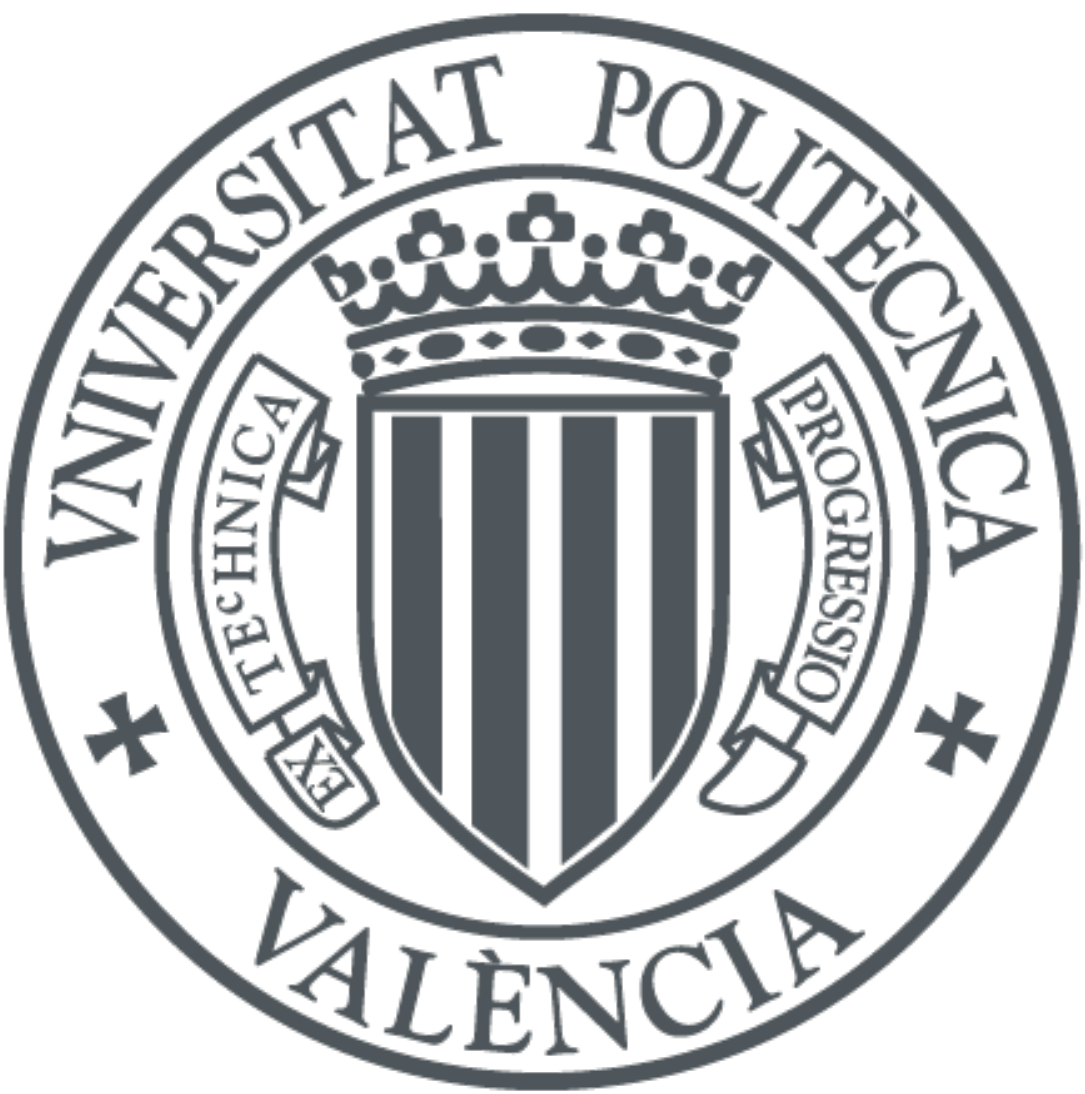

The final publication is available at

https://doi.org/10.1515/jbvela-2018-0012

Copyright De Gruyter

Additional Information 


\title{
Terminal value in SMEs: Testing the multiple EV/EBITDA approach
}

\section{Raül Vidal-Garcia ${ }^{1} /$ Javier Ribal ${ }^{2}$}

1. Universitat Rovira i Virgili, Dep. Gestió d'Empreses, Av. de Remolins, 13 Tortosa (Tarragona), Spain, E-mail: drvidalgarcia@gmail.com. https://orcid.org/0000-00020576-4777.

2. Universitat Politecnica de Valencia, Dep. of Economy and Social Sciences, Camino de Vera s/n 46022 Valencia, Spain, E-mail: frarisan@upv.es. https://orcid.org/0000-00029355-0145.

\begin{abstract}
This study focuses on answering whether EV/EBITDA multiple of public companies in the food industry can be useful to obtain the Terminal Value (TV) in the valuation of unlisted small and medium-sized food companies. A case study into Spanish unlisted agribusinesses is designed for several samples and accounting years from 2010 to 2013. By means of a discounted cash flow (DCF) model combined with bootstrap techniques, the TV/EBITDA empirical distribution of the unlisted multiples is obtained for two different scenarios of free cash flow (FCF) growth, and then compared with the EV/EBITDA of the listed companies in the same industry. The results show that the stock market EV/EBITDA multiple may be used to determine the TV in the valuation process of unlisted small and medium-sized food companies that consistently obtain positive cash flows.
\end{abstract}

Keywords: Terminal value, valuation multiples, SMEs, food companies, EV/EBITDA, bootstrap.

JEL Classification: G12, G34, M41, Q14. 


\section{Introduction}

The method of Discounted Cash Flows (DCF) is widely used in the analysis and valuation of small and medium enterprises (SMEs). Imam et al. (2008) state that most analysts prefer sophisticated valuation models, such as DCF. Demirakos et al. (2010) report that analysts in the UK use DCF models more frequently than Price-Earnings models to value small firms, loss-making firms, and firms with a limited number of industry peers. Petersen et al. (2006), in a study on Danish privately held firms, show that DCF is the preferred method over other present value approaches; Jennergren (2008) confirms that among the members of the discount family, the DCF model has traditionally been the dominant one in practice. In a survey of Czech analysts, Vydrzel and Soukupová (2012) find that 78\% of participants use DCF for private equity valuation.

The standard approach of the DCF is to break down the model in two stages, hence it is called two-stage DCF model (Damodaran, 2006; Koller et al, 2015). The first stage uses explicit forecasted cash flows for a limited number of years, typically around 5 years (Rojo and Garcia, 2006; Petersen et al, 2006). In the second stage it is assumed that the company will return to a 'steady-state'; this stage is termed as 'terminal value' (TV) or 'continuing value' and will have an unlimited duration. According to Beitel (2016), not only do authors disagree on which assumptions to make, but also the fundamental structure of the terminal value calculation is debated. A high-quality estimate of terminal value is critical because it often accounts for a large percentage of the total value of the project in a discounted cash flow valuation. Koller et al. (2015) compared terminal value weights in multiple industries, showing that the terminal value period could even exceed the total value of the company at this point in time. Berkman, et al. (1998), state that this second stage of valuation usually is between 53 and $80 \%$ of company value. However, as a "going concern" basis of the business valuation, it is an integral part of the entire business valuation but is often underestimated in the valuation process ( $\mathrm{Li}, 2017)$.

Several manuals on company valuation, such as Damodaran (2006), Woolley (2009) and Koller et al. (2015), detail the same ways to quantify TV. Namely, liquidation value, stable growth or perpetuity valuation, by means of the Gordon growth model (GGM), and trading multiple approach or terminal multiple (TM). Using a survey of 356 valuation experts across 10 European countries, Bancel and Mittoo (2014) report that 51\% of the respondents rely on a normative terminal cash flow growing until infinity whereas $27 \%$ use a multiple. Vydrzel and Soukupová (2012) indicate that Gordon's model for economic growth is the dominant model for the terminal value calculation together with multiples. Petersen et al (2006) report that $14 \%$ of participants in a survey to private funds and financial equity advisers estimate the terminal value using a multiple such as EV/EBIT or EV/EBITDA.

Damodaran (2006) explains that both approaches, GGM and TM, value the firm as a going concern at the time of the terminal value estimation. Damodaran (2006) thinks that the stable growth model is the soundest option but requires to make judgments about when the firm will grow at a stable rate which it can sustain forever, and the excess returns that it will earn during the period. Rojo-Ramírez et al. (2018) also highlight the difficulty of establishing the growth rate. On the other hand, Damodaran (2006) also thinks that the TM approach is the easiest one although Copeland et al. (2002) state the opposite. Woolley (2009) explains that the TM is rooted in economic values and assumes that the company being valued is average or little is known of it. For this author although it is "quite a common approach" it should only serve as a check and not as the main means of setting a TV. Chapman and Klein (2009) use EBITDA entry and exit multiples as is standard among buyout practitioners.

There are several trading multiples that could be used to determine the TV but most of the authors affirm and prove that the EV/EBITDA is the best one. Having reviewed accounting and finance literature, Bhojraj and Lee (2002) state that there is little evidence to support the selection of specific multiples. However, a number of studies have shown that earnings-based multiples (e.g, P/E, EV/EBITDA) are the most popular valuation methods used in practice (Cascino, 2014). Pinto, et al. (2015) note that EV/EBITDA is overwhelmingly the most popular EV ratio and is clearly a widely used metric in current valuation practice. Martínez and Ortiz 
(2004) think that analysts try to reduce the impact of accounting diversity using less biased ratios, such as EV/EBITDA.

The overwhelming majority (99.8\%) of enterprises active within the EU-28's nonfinancial business economy in 2014 were micro, small and medium-sized enterprises (MSMEs). In a context of information scarcity such as SMEs' valuation, the trading multiple approach is a straight and common resource. Liu et al. (2002) assert that multiples are often used as a substitute to calibrate valuations and to obtain terminal values. For Eberhart (2004), the valuation of equity using multiples of comparables is a highly popular technique.

Taking into account that information on trading multiples of listed companies is easily available, the main objective of this paper is to determine whether listed stock multiples, specifically EV/EBITDA, can be used as a way to quantify the terminal value for Small and Medium Enterprises. To achieve this goal, a case study on Spanish food SMEs has been carried out. By using multiple valuation models we implicitly assume that markets are efficient and trades and transactions reflect fundamental or intrinsic firm values (Bancel and Mittoo, 2014). Rojo et al. (2018) reveal that equity TV calculated by fundamentals constitutes a component of the firm value that the market takes into account.

The rest of the paper is organized as follows: Section 2 details the terminal value model to be used and introduces the different approaches for obtaining the TV to be tested in the empirical work. Section 3 summarizes the data and research design. Section 4 includes the results obtained and finally, section 5 shows the main conclusions.

\section{Terminal value: stable growth models}

The traditional cash flow to perpetuity formula is based on Gordon-Shapiro (1956). The TV is estimated by equation (1), it represents the value of the company's expected cash flow beyond the explicit forecast period (Koller et al, 2015).

$$
T V=\frac{F C F \cdot(1+g)}{(W A C C-g)}
$$

Where FCF: Free Cash Flow, WACC: Weighted Average Cost of Capital, g: annual growth rate.

The estimation of the future cash flows is usually based on the cash flow obtained in the last year with available data. It is possible, as well, to fix the future cash flow as the average of the historic FCF, that is to say, the average mean of the series of FCF.

The annual growth rate is assumed to adjust to the estimated long-term growth rates of the Gross Domestic Product, GDP, (Brealey et al, 2011; Muller and Ward, 2016). Penman (2001) states that, in practice, analysts often apply an assumed growth rate equal to average gross domestic product growth. A more conservative approach is to consider a null growth rate.

Combining, the two ways of obtaining the future FCF with a null growth rate or with a GDP rate, 4 scenarios can be defined.

The Free Cash Flows (FCF) are calculated as shown in equation (2), by means of Earnings before Interest and Taxes (EBIT), corporate tax rate (t), Depreciations and Amortisations (DA), Capital Expenditure (CAPEX) and Changes in the Working Capital (CWC).

$$
F C F=E B I T *(1-t)+D A-C A P E X-C W C
$$


The FCF are discounted by using the Weighted Average Cost of Capital (WACC), equation (3).

$$
W A C C=k_{e} * \frac{E}{(E+D)}+k_{d} *(1-t) * \frac{D}{(E+D)}
$$

Where, E: equity, D: Debt, ke: cost of equity and kd: Cost of Debt.

The cost of equity (ke) is typically calculated using the CAPM, by unlevering and levering the beta coefficient (Breuer et al, 2014). The risk-free rate has been estimated by using the 10-year Spanish Bond (Bank of Spain, 2016), while the market risk premium has been obtained as the geometric mean of the excess of return of the IGBM (Madrid Stock Market General Index) over the risk-free rate.

The unlevered beta of the listed food sector is obtained as the average of the individual betas. Then the individual betas for each SME are computed by levering the unlevered beta of the listed companies by means of the Hamada formula (Hamada, 1972). Petersen et al. (2006) also report the use of this formula in the valuation of privately-held firms. For the valuation of each company, the levered beta is computed by using the capital structure. The weights of the capital structure in the WACC equation are based on the accounting book information of each company. The food industry cost of debt has been obtained by the financial costs and interestbearing liabilities of the base year. Petersen et al. (2006) report that the valuation of privatelyheld firms often involves investors who are not well-diversified. With our approach, a welldiversified investor is assumed; nevertheless, additional corrections to the fundamental multiples could be introduced later on. Some authors proposed to add some spread to the cost of equity in order to reflect higher risk or lack of marketability; Alonso and Rojo (2011) made a very good literature revision on the topic.

\section{Data and research design}

A case study has been developed using SMEs food companies. The European food industry is mostly characterized by Small and Medium-sized Enterprises (SMEs); as of 2013, SMEs represented $99.13 \%$ of the total number of companies (Eurostat, 2016). Therefore, it is a suitable industry as regards to this paper's goal. This same pattern is repeated throughout the world. In the OECD area, SMEs are the predominant form of enterprise, accounting for approximately $99 \%$ of all firms (OECD, 2017); Pandya (2012) refers $99 \%$ of business in US are SMEs, while $80 \%-90 \%$ of companies in Latin American and Caribbean area (LAC), are micro enterprises. This author also states that in Japan, the contribution of SMEs is $99 \%$ of total business. Xiangfeng (2007) reports that SMEs made up for $99.7 \%$ of the total number of companies operating in China.

The study covers four different base years (2010, 2011, 2012 and 2013) and uses two main data sources of food companies.

On the one hand, the accounting data of unlisted Spanish food companies which have been obtained from a database, specifically the 'Iberian Balance Analysis System' (SABI). Food industry weights $7 \%$ of the Spanish GDP and it is a typical example of an industry made up mostly by small and medium enterprises.

On the other hand, quoted food companies which data have been obtained from the European stock markets instead of only using the Spanish quoted food companies. Currently, there are 8 listed companies in the Food industry in Spain. This figure was even lower in the years of this study (around 6 companies) and it has been deemed insufficient to carry out the contrast. 
Accounting and market data of listed European food companies from 2005 to 2013 have been gathered from the Damodaran website (2014) under the industry group of food processing. None of the data sources includes beverage manufacturers. The Spanish companies made up $4.14 \%$ of the companies of the listed sample.

The unlisted Spanish companies have been selected, taking those Limited Companies whose main NACE code is C10 (Manufacture of food products). The NACE is the statistical classification of economic activities in the EU. The companies that make up the food industry exhibit great variability in terms of capital, turnover or results. For that reason, working from the whole sample, two subsamples have been considered in order to gain some homogeneity.

- Whole sample. Unlisted (privately held) Spanish food companies with a turnover of over 2 million Euros. Imposing this condition on turnover excludes companies classified as micro-companies according to the EU recommendation 2003/361. The main reason for discarding those companies is to ensure better quality accounting data.

- Small and Medium Enterprises (SMEs). Those companies with a turnover of fewer than 50 million Euros have been selected from the whole sample. According to the definition of a SME in the EU recommendation 2003/361, a turnover of 50 million euros is the maximum established amount.

- Success bias SMEs. Those companies with positive free cash flow in each of the 5 years prior to the base year have been drawn from the previous category sample.

The sample of unlisted food companies is made up of those companies with accounting data for the base years. For each base year, 5 years of historical data are needed. Table 1 gathers the number of companies for each sample and base year. It also shows the number of food manufacturing companies listed in the European markets. Those companies with incomplete, inconsistent or illogical data have been removed. In addition, those companies with negative EBIT have been filtered (Damodaran, 2006; Liu et al, 2002).

Table 1. Sample size according to the base year

\begin{tabular}{cccccc}
\hline Base & Historical & Whole & \multicolumn{2}{c}{ Unlisted food SMEs } & Listed food \\
year & data & sample & SMEs & SMEs with FCF > 0 & companies \\
\hline 2010 & $2005-2009$ & 1,639 & 1,504 & 122 & 84 \\
2011 & $2006-2010$ & 1,663 & 1,510 & 140 & 75 \\
2012 & $2007-2011$ & 1,732 & 1,560 & 137 & 91 \\
2013 & $2008-2012$ & 1,801 & 1,627 & 265 & 94 \\
\hline
\end{tabular}

Table 2 shows the main financial ratios of the samples, debt ratio, return on assets and return on equity for the four base years. All the ratios have been computed using book magnitudes. Listed and successful SMEs show a similar grade of indebtedness which is lower than the one in the other two samples. As regards to return ratios, listed companies have greater returns than the rest of the samples although the sample of successful SMEs has got returns much higher than the other unlisted samples. 
Table 2. Main financial ratios

\begin{tabular}{|c|c|c|c|c|}
\hline \multirow{2}{*}{$\begin{array}{l}\text { Base } \\
\text { year }\end{array}$} & \multirow{2}{*}{$\begin{array}{l}\text { Whole } \\
\text { sample }\end{array}$} & \multicolumn{2}{|c|}{ Unlisted food SMEs } & \multirow{2}{*}{$\begin{array}{c}\text { Listed food } \\
\text { companies }\end{array}$} \\
\hline & & SMEs & SMEs with FCF $>0$ & \\
\hline \multicolumn{5}{|c|}{ Debt ratio } \\
\hline 2010 & $56.1 \%$ & $51.5 \%$ & $30.9 \%$ & $40.2 \%$ \\
\hline 2011 & $56.0 \%$ & $52.0 \%$ & $34.6 \%$ & $34.9 \%$ \\
\hline 2012 & $55.4 \%$ & $50.5 \%$ & $33.6 \%$ & $35.6 \%$ \\
\hline 2013 & $53.3 \%$ & $50.2 \%$ & $42.1 \%$ & $39.1 \%$ \\
\hline \multicolumn{5}{|c|}{ Return on Assets } \\
\hline 2010 & $7.3 \%$ & $6.6 \%$ & $13.7 \%$ & $15.3 \%$ \\
\hline 2011 & $7.3 \%$ & $6.2 \%$ & $12.2 \%$ & $15.9 \%$ \\
\hline 2012 & $6.9 \%$ & $6.0 \%$ & $12.7 \%$ & $15.2 \%$ \\
\hline 2013 & $6.3 \%$ & $6.0 \%$ & $9.4 \%$ & $16.2 \%$ \\
\hline \multicolumn{5}{|c|}{ Return on Equity } \\
\hline 2010 & $12.2 \%$ & $8.8 \%$ & $14.5 \%$ & $17.8 \%$ \\
\hline 2011 & $11.6 \%$ & $8.1 \%$ & $14.0 \%$ & $33.4 \%$ \\
\hline 2012 & $10.3 \%$ & $7.9 \%$ & $14.4 \%$ & $15.6 \%$ \\
\hline 2013 & $9.7 \%$ & $7.7 \%$ & $11.6 \%$ & $17.0 \%$ \\
\hline
\end{tabular}

\subsection{Contrast of the null hypothesis}

The null hypothesis $\left(\mathrm{H}_{0}\right)$ of the case study is that there is not a significant difference between the SMEs' terminal value obtained by means of the Gordon Model and the terminal value obtained by means of the EV/EBITDA multiple from quoted companies.

$$
H_{0}: T V_{S M E}=\frac{E V_{\text {Listed Companies }}}{E B I T D A_{\text {Listed } \text { Companies }}} \cdot E_{B I T D A_{S M E}}
$$

In order to work with relative values instead absolute ones, the $\mathrm{H}_{0}$ is transformed by dividing both sides by EBITDASME:

$$
\text { Alternative } H_{0}: \frac{T V_{S M E}}{E B I T D A_{S M E}}=\frac{E V_{\text {Listed Companies }}}{E B I T D A_{\text {Listed Companies }}}
$$

It should be noticed that the null hypothesis compares SMEs and public companies, and that the current EV/EBITDA is used to calculate the terminal value. These two points make the hypothesis interesting to contrast as the EV/EBITDA from public companies is commonly used for SMEs.

Instead of computing the mean of the TV/EBITDA multiple, the statistical contrast is based on the harmonic weighted average method (Morningstar, 2005) for calculating the TV/EBITDA multiple of the industry. This is equivalent to computing the industry TV/EBITDA as shown in equation (4).

$T V / E B I T D A_{S M E}$ food industry $=\frac{1}{\frac{E B I T D A_{1}}{T V_{1}} * W_{1}+\frac{E B I T D A_{2}}{T V_{2}} * W_{2}+\cdots+\frac{E B I T D A_{n}}{T V_{n}} * W_{n}}$ 


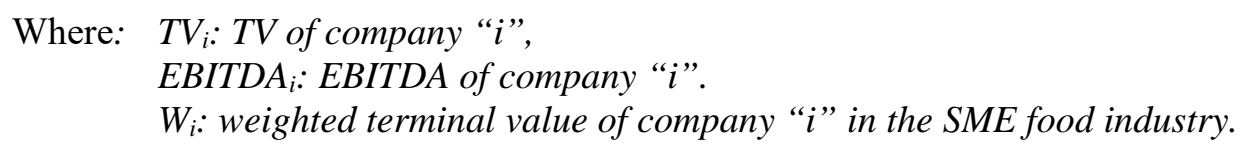

In the same way the EV/EBITDA for the food listed companies is computed.

Using the harmonic weighted average have some advantages, such as showing less sensitivity to the presence of outliers, which can easily distort the results in average multiples (Vakili and Schmitt, 2014). Liu et al. (2002) also reported that performance improves when multiples are computed using the harmonic mean, when compared with the arithmetic mean or the median. For Agrrawal et al. (2010), the portfolio harmonic mean of the P/E multiple is the logical approach to averaging valuation multiples.

\subsection{Bootstrap procedure}

In order to test the difference (alternative $\mathrm{H}_{0}$ ) a bootstrap technique has been used. Bootstrapping is a technique that resamples from the original data set (Efron, 1979) allowing any lack of normality issues to be avoided. Bootstrap methods have many applications for certain kinds of computations, such as biases, standard errors and confidence limits (Chernick and LaBudde, 2014).

The implementation of the bootstrap, together with the harmonic weighted average TV/EBITDA (EV/EBITDA) ratio, has been carried out as follows.

Each variable of the fundamental model applied to unlisted companies is resampled, the bootstrap mean is obtained and the procedure is replicated 10,000 times. At the same time, the EBITDA is also bootstrapped. A matrix is obtained, made up of the valuation parameters and the EBITDA as columns and each bootstrap replicate in rows. For each row, the mean terminal value is worked out. Using those 10,000 mean terminal values and the corresponding EBITDA, the empirical bootstrap distribution for the mean TV/EBITDA ratio is built. In the same way, the empirical bootstrap distribution for listed stock EV/EBITDA ratio has been determined by bootstrapping Enterprise Values and EBITDAs. Table 3 summarizes the bootstrap procedure.

Table 3. Average company TV/EBITDA

1. Bootstrapping the mean of the valuation model parameters (10,000 Times).

2. Calculation of the distribution of the mean value (10,000 Values).

3. Calculation of the distribution of the mean for each fundamental and stock multiple (10,000 multiples).

4. Contrasting statistical differences in the mean.

In order to ensure that all of the companies are considered in every run of the bootstrap process, a stratified resampling has been used (Davidson and Hinkley, 1997). The criterion to form the strata is the fiscal number of the company.

\subsection{Determination of the free cash flows}

When estimating the future FCFs of the second stage in the valuation of private companies, there is no analysts' prediction available. The historic FCFs have been used as the first stage FCFs and they will be the key element to forecast the final cash flow to be used in the second stage. Two different forecasting hypotheses have been used. Both hypotheses try to mimic the different ways that valuation professionals can estimate the FCFs of a private company valuation: Using the average of the first stage FCFs and using the last FCF of the first stage. Both are a practical compromise in a context of mass valuation since an analyst would use information of the last years and future expectations to build his/her projections. The two 
hypotheses use a bootstrap technique to obtain 10,000 possible future values of the FCF of the average company. Every possible FCF will be used to determine the terminal value (TV) according to equation (1) in each sample. Furthermore, this procedure has been carried out for each different time windows, considering the four different base years from 2010 to 2013. Table 4 shows the layout of valuation time windows to be used for each base year.

Table 4. Layout of valuation time windows

\begin{tabular}{ccc}
\hline $\begin{array}{c}\text { Historical } \\
\text { data }\end{array}$ & $\begin{array}{c}\text { Base } \\
\text { year }\end{array}$ & $\begin{array}{c}\text { Terminal value } \\
\text { (Forecasting) }\end{array}$ \\
\hline $2005: 2009$ & 2010 & $2011-\ldots$ \\
$2006: 2010$ & 2011 & $2012-\ldots$ \\
$2007: 2011$ & 2012 & $2013-\ldots$ \\
$2008: 2012$ & 2013 & $2014-\ldots$ \\
\hline
\end{tabular}

The long-term growth is fixed by taking the Spanish GDP series from 1996 to the base year. A bootstrap procedure is applied to compute the empirical distribution of the average GDP. Each bootstrap replicate is applied to the FCF of the base year in the TV Gordon growth formula.

\subsection{Determination of the terminal value multiple}

Once the 10,000 EVs of the average company are obtained for each Gordon model, it is straightforward to work out the empirical distribution of the TV/EBITDA multiple for each base year and hypotheses by dividing by the EBITDA. Figure 1 shows the outlay of the model application. 
Terminal value approaches in the valuation of food Spanish SMEs

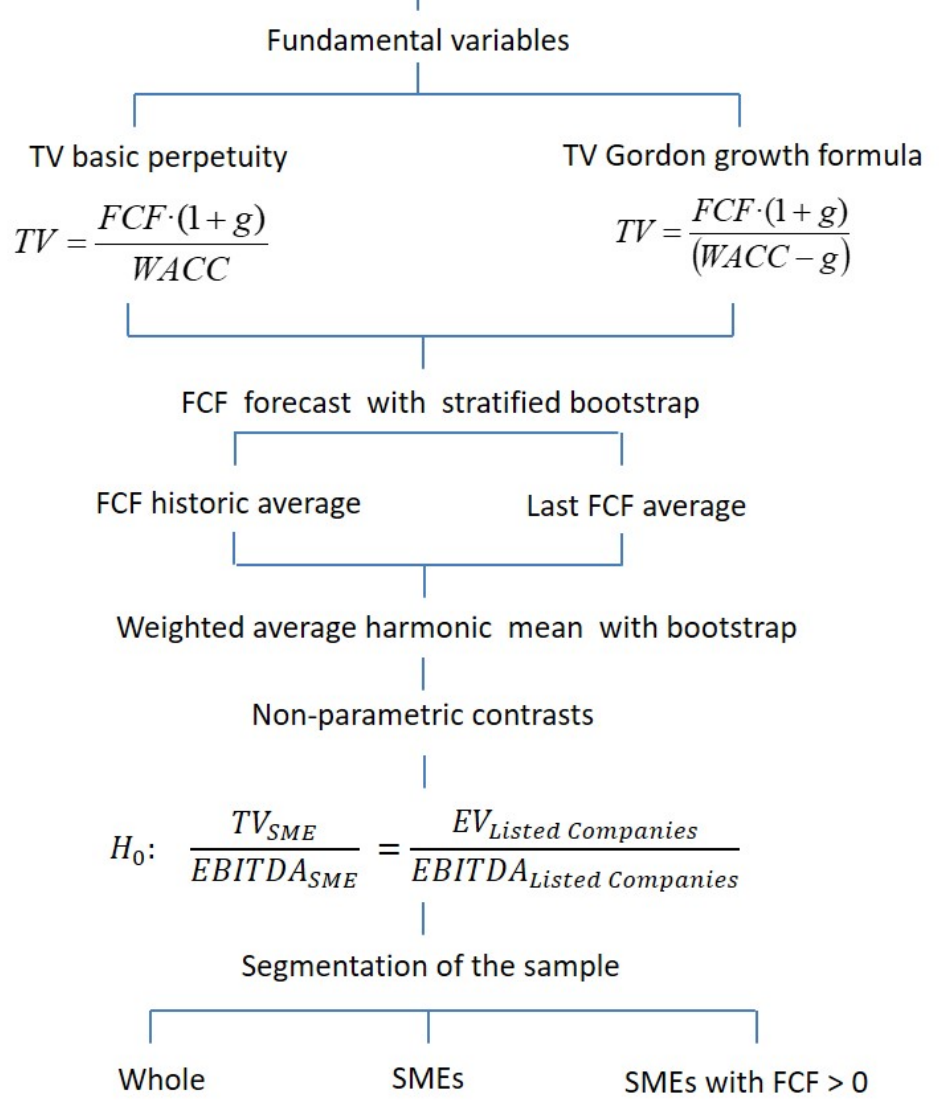

Figure 1. Outline of the procedure

Therefore, based on Figure 1 there are a total of 48 results (48 bootstrap empirical distributions of the average terminal values). Those 48 results come out from the combination of 2 models proposed on Gordon valuation ("TV basic perpetuity" and "TV Gordon growth formula") for 2 FCF calculation scenarios ("Average bootstrap of the historic FCF" and "Bootstrap of the last FCF"), applicable each one of them at 4 base years (2010: 2013) object of research, and for each of the 3 segments of the sample worked ("Whole", "SMEs" and "SMEs with $\mathrm{FCF}>0$ "), hence $2 \times 2 \times 4 \times 3=48$ results.

\section{Results}

Since the model has been applied to three samples, with two different FCF growth scenarios and for two valuation models proposed, the results can be interpreted following those three dimensions. The use of four different time windows allows the robustness of the solutions to be tested.

\subsection{Testing the null hypothesis}

The null hypothesis states that there is no significant difference between the Terminal Value / EBITDA of food SME companies and the EV/EBITDA of listed food companies. Table 5 shows the average fundamental TVSME / EBITDAsme ratio together with the stock market EV/EBITDA multiple for the four study years and the aforementioned dimensions. 
Table 5. Average TV/EBITDA Null hypothesis contrast

\begin{tabular}{|c|c|c|c|c|c|c|}
\hline \multirow{2}{*}{ Sample } & \multirow{2}{*}{$\begin{array}{l}\text { Base } \\
\text { year }\end{array}$} & \multirow{2}{*}{$\begin{array}{c}\text { Stock } \\
\text { exchange }\end{array}$} & \multicolumn{2}{|c|}{$\begin{array}{c}\text { TV basic } \\
\text { perpetuity }\end{array}$} & \multicolumn{2}{|c|}{$\begin{array}{l}\text { TV Gordon } \\
\text { growth formula }\end{array}$} \\
\hline & & & $\begin{array}{c}\text { FCF } \\
\text { historic average }\end{array}$ & $\begin{array}{l}\text { Last } F C F \\
\text { average }\end{array}$ & $\begin{array}{c}\text { FCF } \\
\text { historic average }\end{array}$ & $\begin{array}{c}\text { Last } \mathbf{F C F} \\
\text { average }\end{array}$ \\
\hline \multirow{4}{*}{$\frac{0}{\stackrel{0}{\varrho}}$} & 2010 & 11.38 & 4.15 & 6.37 & 7.13 & 10.94 \\
\hline & 2011 & 9.72 & 3.59 & 2.04 & 5.44 & 3.09 \\
\hline & 2012 & 11.40 & 3.93 & 6.68 & 5.63 & 9.58 \\
\hline & 2013 & 12.79 & 4.75 & 5.64 & 6.52 & 7.75 \\
\hline \multirow{4}{*}{$\sum_{\infty}^{\infty}$} & 2010 & 11.38 & 1.11 & 3.78 & 1.97 & 6.7 \\
\hline & 2011 & 9.72 & 1.16 & 1.93 & 1.81 & 3.02 \\
\hline & 2012 & 11.40 & 1.34 & 3.05 & 1.99 & 4.51 \\
\hline & 2013 & 12.79 & 3.09 & 5.03 & 4.32 & 7.05 \\
\hline \multirow{4}{*}{ 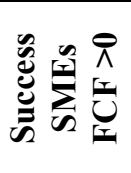 } & 2010 & 11.38 & 8.09 & 8.98 & 13.61 & 15.12 \\
\hline & 2011 & 9.72 & 8.06 & 7.64 & 12.22 & 11.58 \\
\hline & 2012 & 11.40 & 8.31 & 7.95 & 11.81 & 11.29 \\
\hline & 2013 & 12.79 & 9.32 & 9.69 & 13.03 & 13.55 \\
\hline
\end{tabular}

*Bold values mean that the public stock EV/EBITDA and the SME's TV/EBITDA exhibit statistical differences. $p \leq 0.05$

Private companies' multiples are in average lower than the public ones as depicted in table 5. The use of a cost of capital similar to the one expected for public companies produces a Value /EBITDA lower for SMEs. This means that in average terms the return and value creation is lower for SMEs.

With respect to the FCF growth hypotheses, using "the Bootstrap of the last FCF" seems to be slightly better than using "Average bootstrap of the historic FCF" to determine TV/EBITDA. In this sense, the FCF bootstrap of the last year shows fewer cases with statistically significant differences.

If the results are analyzed from the point of view of the use of the growth rate "g", the inclusion of the growth rate "g" according to the GDP shows fewer cases with significant differences. Specifically, the TV/EBITDA for the sample of SMEs with positive FCF and growth according to GDP does not show significant differences in any of the four years regardless of how the FCFs are obtained.

As regards the sample, the null hypothesis cannot be rejected in any of the cases in the sample of SMEs. Considering the whole sample, no significant difference has been found in half of the cases. If only the successful SMEs are taken into account, the null hypothesis is rejected in $33 \%$ of the cases.

The use of bootstrap allows empirical distributions to be obtained and hence the hypothesis to test can be plotted. Figure 2 and figure 3 show the empirical distribution of the average TV/EBITDA for unlisted companies and the average EV/EBITDA for stock companies using the SME sample with positive past FCF. Similar plots could be built for the rest of the cases. 
$\square$ TV/EBITDA unlisted companies $\square$ EV/EBITDA listed companies

2010

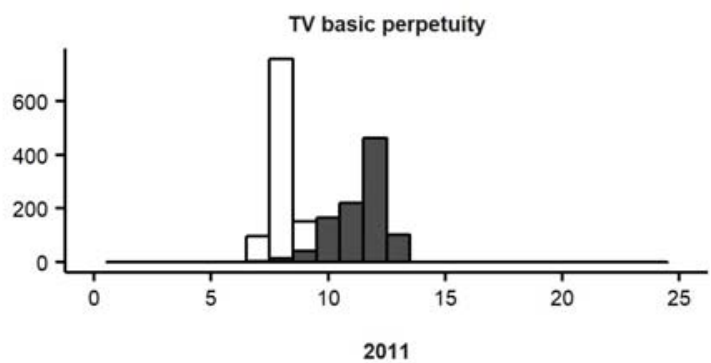

TV basic perpetuity

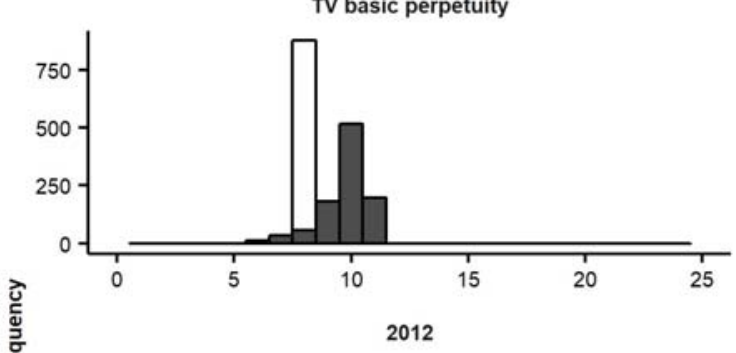

TV basic perpetuity

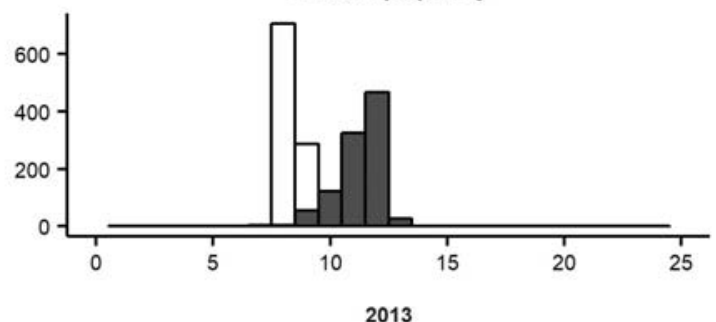

TV basic perpetuity

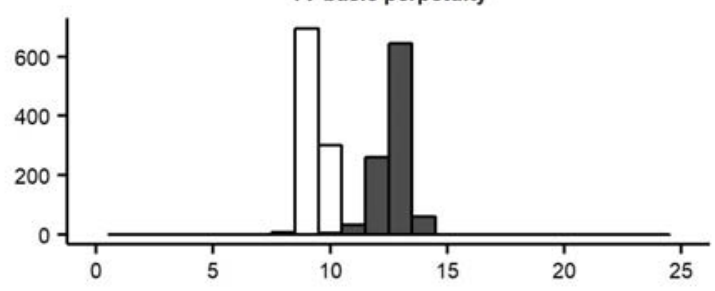

2010

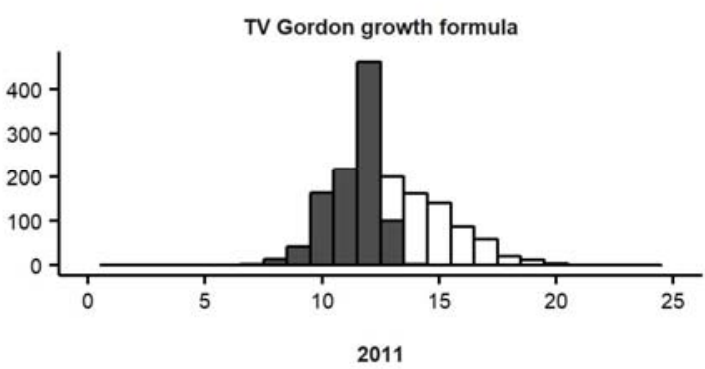

TV Gordon growth formula

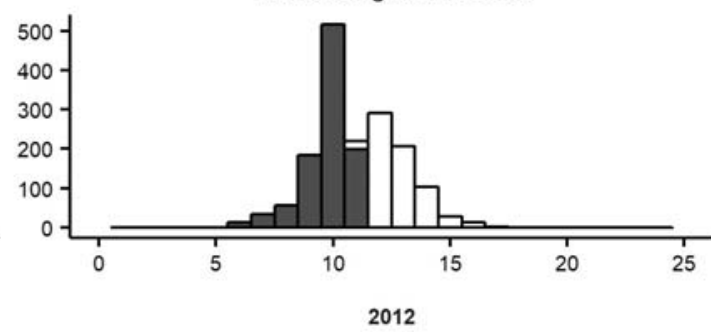

TV Gordon growth formula

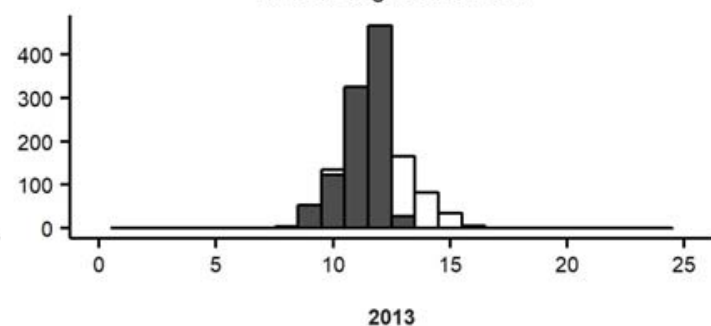

TV Gordon growth formula

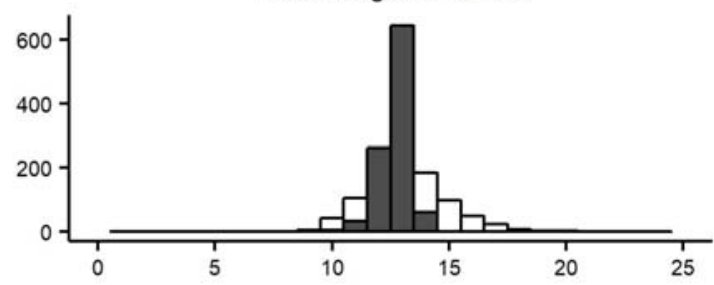

Figure 2. Hypothesis contrast: SME with positive FCF using the average FCF in the Gordon Model 
TV/EBITDA unlisted companies $\square$ EV/EBITDA listed companies

2010

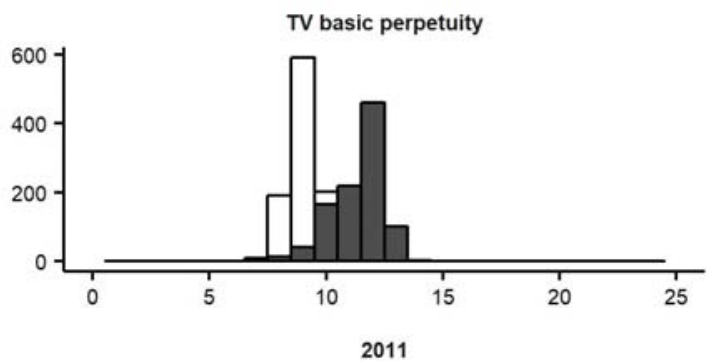

TV basic perpetuity

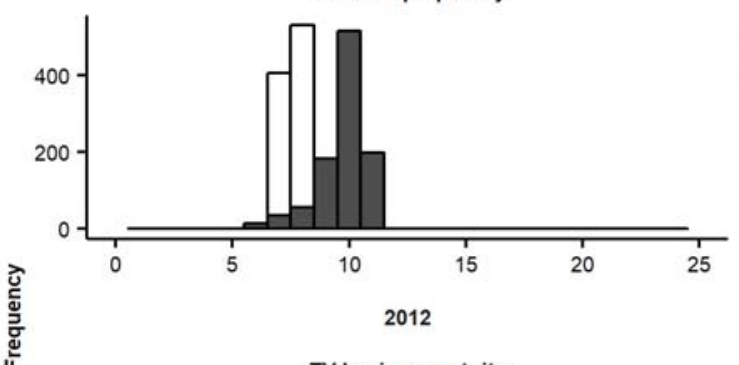

TV basic perpetuity

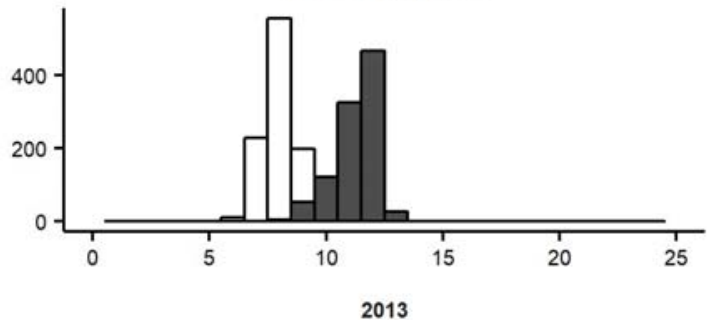

TV basic perpetuity

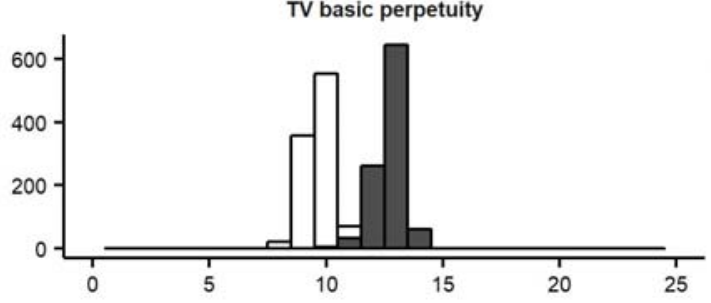

2010
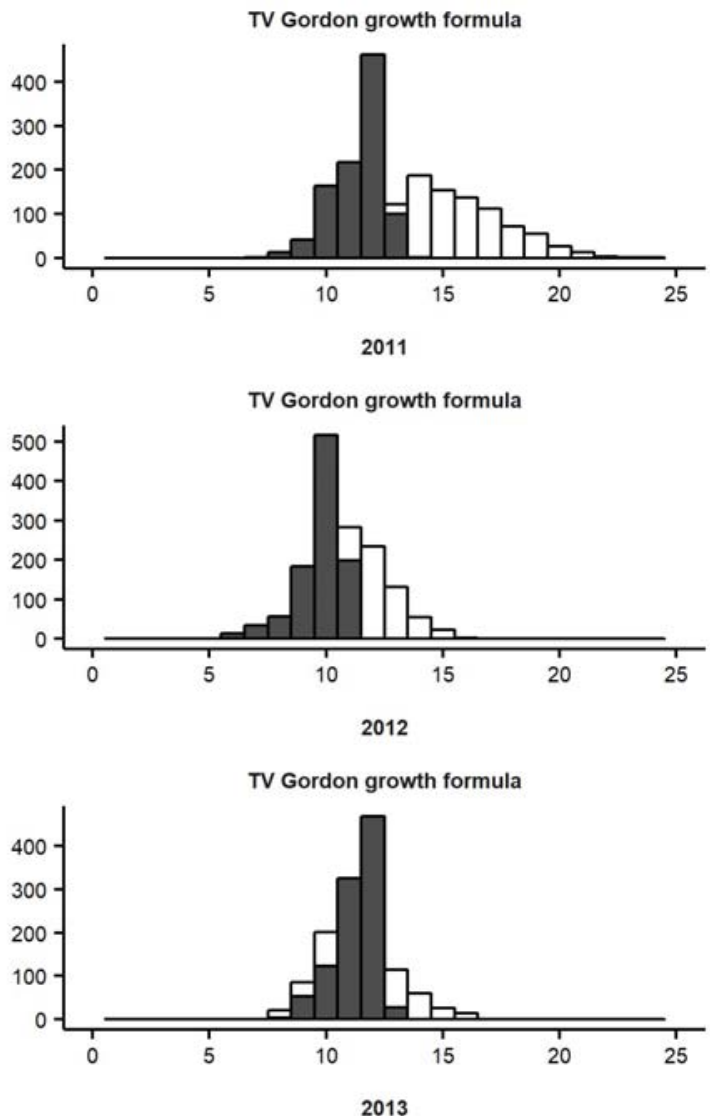

TV Gordon growth formula

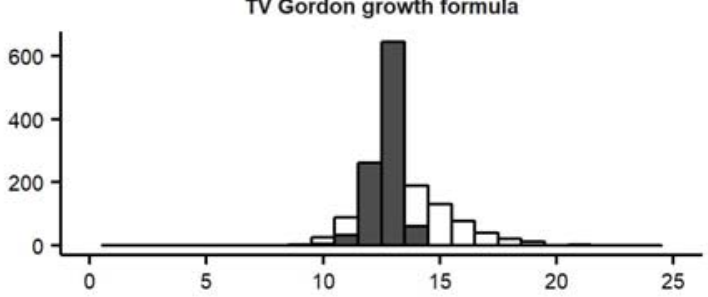

Figure 3. Hypothesis contrast: SME with positive FCF using the last FCF in the Gordon Model

The whole analysis has been also carried out using the median instead of the harmonic weighted average (table 6). For the private companies the EV/EBITDA results are quite similar to the table 5. However, for public companies, with a much smaller sample size, the median EV/EBITDA is much lower for all the years and the hypothesis contrast show less significant differences. This second analysis highlights the importance of how the industry multiple is defined.

Table 6. Median TV/EBITDA null hypothesis contrast

\begin{tabular}{|c|c|c|c|c|c|c|}
\hline \multirow{2}{*}{ Sample } & \multirow{2}{*}{$\begin{array}{l}\text { Base } \\
\text { year }\end{array}$} & \multirow{2}{*}{$\begin{array}{c}\text { Stock } \\
\text { exchange }\end{array}$} & \multicolumn{2}{|c|}{$\begin{array}{l}\text { TV basic } \\
\text { perpetuity }\end{array}$} & \multicolumn{2}{|c|}{$\begin{array}{l}\text { TV Gordon } \\
\text { growth formula }\end{array}$} \\
\hline & & & $\begin{array}{c}\text { FCF } \\
\text { historic average }\end{array}$ & $\begin{array}{c}\text { Last FCF } \\
\text { average }\end{array}$ & $\begin{array}{c}\text { FCF } \\
\text { historic average }\end{array}$ & $\begin{array}{c}\text { Last } F C F \\
\text { average }\end{array}$ \\
\hline
\end{tabular}




\begin{tabular}{|c|c|c|c|c|c|c|}
\hline \multirow{4}{*}{ 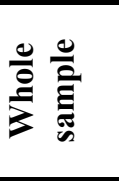 } & 2010 & 5.97 & 4.19 & 3.95 & 7.20 & 6.80 \\
\hline & 2011 & 5.69 & 3.65 & 2.56 & 5.59 & 3.92 \\
\hline & 2012 & 8.36 & 4.18 & 3.18 & 6.19 & 4.71 \\
\hline & 2013 & 9.92 & 5.08 & 4.73 & 7.15 & 6.65 \\
\hline \multirow{4}{*}{$\sum_{\infty}^{\infty}$} & 2010 & 5.97 & 1.05 & 4.04 & 1.81 & 6.94 \\
\hline & 2011 & 5.69 & 1.13 & 2.70 & 1.74 & 4.17 \\
\hline & 2012 & 8.36 & 1.35 & 3.40 & 2.00 & 5.04 \\
\hline & 2013 & 9.92 & 3.15 & 4.78 & 4.45 & 6.75 \\
\hline \multirow{4}{*}{ 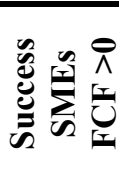 } & 2010 & 5.97 & 8.27 & 9.33 & 14.24 & 16.05 \\
\hline & 2011 & 5.69 & 8.05 & 7.32 & 12.15 & 11.06 \\
\hline & 2012 & 8.36 & 8.50 & 7.74 & 12.25 & 11.16 \\
\hline & 2013 & 9.92 & 9.41 & 10.06 & 13.20 & 14.11 \\
\hline
\end{tabular}

*Bold values mean that the stock EV/EBITDA median and the fundamental TV/EBITDA median exhibit statistical differences. $p \leq 0.05$

\section{Conclusions}

This study focuses on answering whether listed stock valuation multiples of the food industry can be useful to obtain the Terminal Value (TV) in the valuation of unlisted small and medium-sized food companies. The Gordon model of discounted cash flows in perpetuity is applied on unlisted Spanish food companies in order to obtain distributions of the TV/EBITDA ratio of the average food company. This ratio is compared with the average EV/EBITDA multiple of listed companies, if no significant difference is found, then the EV/EBITDA multiple can be successfully used for estimating the terminal value of SMEs.

Our results show that the EV/EBITDA from stock market multiples should not be used in the valuation process of the terminal value of unquoted food companies. The difference might be caused by differences in growth and profitability. Gavious and Parmet (2010) in a study comparing private company and public company valuations found lower growth prospects for private firms expressed in lower research and development intensity. Plenborg and Pimentel (2016) notice that smaller firms are characterized less information availability and inadequate controls and reporting systems. These same authors also gather some references that show how larger firms yield more accurate estimates of value than smaller ones.

However, the stock market EV/EBITDA multiple may be used for quantifying the terminal value of those unlisted small and medium-sized food companies that are consistently obtaining positive free cash flows. The robustness of these findings is asserted by testing them for four different base years (2010-2013).

As regards methodology, the use of the harmonic weighted average together with the bootstrap allows TV/EBITDA average for SMEs and their variability to be estimated.

Further research should be devoted to other industries and to the way of computing the industry multiple in order to check whether these conclusions could be extended. 


\section{References}

Agrrawal, P., Borgman, R., Clark, J.M., and Strong, R. 2010. "Using the Price-to-Earnings Harmonic Mean to Improve Firm Valuation Estimates". Journal of Financial Education 37: 98-110.

Alonso, J., and Rojo, A. A. 2011. "The discount rate in valuing privately held companies". Business Valuation Review 30(2): 70-81.

Bancel, F., and Mittoo, U.R. 2014. "The gap between the theory and practice of corporate: valuation: survey of European experts." Journal of Applied Corporate Finance 26 (4):106-117.

Beitel, T.D. 2016. Terminal value calculations with the discounted cash flow model: differences between literature and practice. Master's thesis, University of Twente.

Berkman, H., Bradbury, M.E., and Ferguson, J. 1998. "The magic of earnings in terminal value calculations." Journal of Financial Statement Analysis 3 (4):27-33.

Bhojraj, S., and Lee, C. 2002. "Who is my peer? A valuation based approach to the selection of comparable firms." Journal of Accounting Research 40 (2):407-439.

Brealey, R.A., Myers, S.C., Allen, F., and Mohanty, P. 2011. Principles of Corporate Finance. McGraw-Hill Education.

Breuer, W., Fuchs, D., and Mark, K. 2014. "Estimating cost of capital in firm valuations with arithmetic or geometric mean or better Use the cooper estimator." The European Journal of Finance 20 (6):568-594.

Cascino, S., Clatworthy, M., Garcia, O.B., Gassen, J., Imam, S., and Jeanjean, T. 2014. "Who uses financial reports and for what purpose? Evidence from capital providers." Accounting in Europe 11 (2):189-205.

Chapman, J. L., and Klein, P. G. 2009. "Value creation in middle-market buyouts: A transaction-level analysis". In Private equity: Fund types, risks and returns, and regulation (Vol. 10). Cumming, D. (Ed.). John Wiley and Sons.

Chernick, M., and LaBudde, R. 2014. An Introduction to Bootstrap Methods with Applications to R. John Wiley \& Sons.

Copeland, T, Koller, T., and Murrin, J. 2000. Valuation: Measuring and Managing the Value of Companies. $3^{\circ}$ edition. John Wiley \& Sons.

Damodaran, A. 2006. Damodaran on Valuation. Wiley Finance, New York.

Davidson, A., and Hinkley, D. 1997. Bootstrap Methods and their Application. Cambridge University Press.

Demirakos, E.G., Strong, N.C., and Walker, M. 2010. "Does valuation model choice affect target price accuracy?" European Accounting Review 19 (1):35-72.

Eberhart, A.C. 2004. "Equity valuation using multiples". The Journal of Investing 13 (2):48-54.

Efron, B. 1979. "Bootstrap methods: Another look at jackknife." Annual Statistics 7 (2):1-26.

Gavious, I., and Parmet, Y. 2010. "Do private firm valuations contain incremental information content over routine analyst valuations?". Research in International Business and Finance 24(2): 223-234.

Gordon, M.J., and Shapiro, E. 1956. "Capital equipment analysis: the required rate of profit." Management Science 3 (1):102-110.

Hamada, R.S. 1972. "The Effect of the Firm's Capital Structure on the Systematic Risk of Common Stocks". The Journal of Finance 27(2):435-452.

Imam, S., Barker, R., and Clubb, C. 2008. "The use of valuation models by UK investment analysts." European Accounting Review 17 (3):503-535.

Jennergren, L. 2008. "Continuing value in firm valuation by the discounted cash flow model." European Journal of Operational Research 185 (3):1548-1563. 
Koller, T., Goedhart, M.., and Wessels, D. 2015. Valuation: Measuring and Managing the Value of Companies. John Wiley \& sons.

Li, W.S. 2017. Strategic Management Accounting: A Practical Guidebook with Case Studies. Springer Singapore Pte. Limited, Singapore.

Liu, J., Nissim, D., and Thomas, J. 2002. "Equity valuation using multiples." Journal of Accounting Research 40 (1):135-172.

Martínez, I., and Ortiz, E. 2004. "International financial analysis and the handicap of accounting diversity." European Business Review 16 (3):272-291.

Morningstar. 2005. Average Price Ratios. Morningstar methodology paper, August 31.

Muller, C., and Ward, M. 2016. "The Implied growth rate in the valuation of JSE listed companies." https://ssrn.com/abstract=2739677.

OECD. 2017. Entrepreneurship at a Glance 2017, OECD Publishing, Paris.

Pandya, V. 2012. Comparative analysis of development of SMEs in developed and developing countries. The 2012 International Conference on Business and Management.

Penman, S.H. 2001. "On comparing cash flow and accrual accounting models for use in equity valuation: a response to Lundholm and O'Keefe." Contemporary Accounting Research 18 (4):681-692.

Petersen, C., Plenborg, T., and Scholer, F. 2006. "Issues in valuation of privately held firms." The Journal of Private Equity 10 (1):33-48.

Plenborg, T., and Pimentel, R. C. 2016. "Best practices in applying multiples for valuation purposes". The Journal of Private Equity 19(3): 55-64.

Pinto, J.E., Robinson, T.R., and Stowe, J.D. 2015. "Equity valuation: A survey of professional practice." https://ssrn.com/abstract=2657717.

Rojo, A., and García, D. 2006. "La Valoración de Empresas en España: Un estudio empírico." Revista Española de Financiación y Contabilidad 35 (132):913-934.

Rojo-Ramírez, A. A., Martínez-Romero, M. J., and Mariño-Garrido, T. 2018. "How the Equity Terminal Value Influences the Value of the Firm?" Journal of Business Valuation and Economic Loss Analysis 13(1).

Vakili, K., and Schmitt, E. 2014. "Finding multivariate outliers with FastPCS." Computational Statistics \& Data Analysis 69 (1):54-66.

Vydrzel, K., and Soukupová, V. 2012. "Empirical examination of valuation methods used in private equity practice in the Czech Republic." The Journal of Private Equity 16 (1):8399.

Woolley, S. 2009. Sources of Value: A Practical Guide to the Art and Science of Valuation. Cambridge University Press, Cambridge.

Xiangfeng, L. 2007. "SME development in China: A policy perspective on SME industrial clustering. Asian SMEs and Globalization". ERIA Research Project Report, 5. 